\title{
USING A LOW-COST AGRICULTURE WASTE FOR CATIONIC DYE REMOVAL FROM AN AQUEOUS SOLUTION: EQUILIBRIUM SORPTION E. Ashour, Maha A. Tony
}

\begin{abstract}
Bare palm fibre was investigated for its ability to perform as a suitable sorbent for methylene blue dye from an aqueous solution. The effect of sorbent dose and temperature was investigated using a batch sorption technique. The results revealed the potential of palm fibre, an agricultural waste, as a low-cost sorbent for the dye examined. The isotherm data were closely fitted to the Langmuir and Frendlich equations and the dye sorption capacity of palm increased as the sorbent dose decreased. Maximum saturated monolayer sorption capacity of bare palm branches for methylene blue dye was investigated. Reaction parameters such as change in particle size of the sorbent material, sorbent mass, air flow rate, initial dye concentration and the medium temperature were also evaluated. In addition, relationships between sorbent dose and Langmuir; Frendlich constants were developed and are presented. The principal conclusions of the study are that the reaction follows the pseudo first order reaction kinetics.

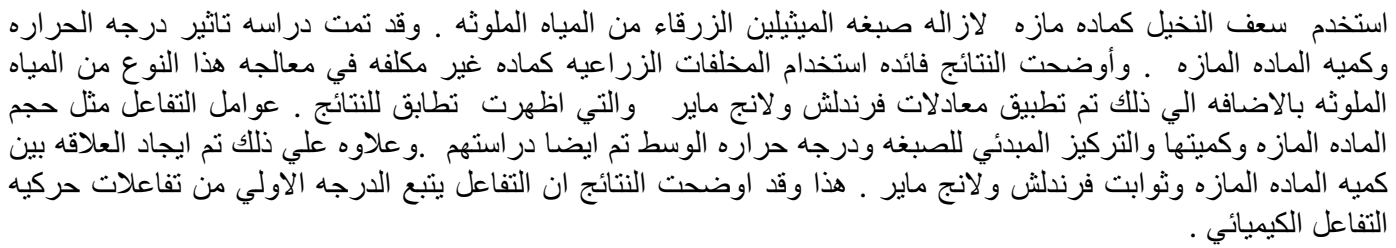

Keywords: bare palm branches, sorption, dye, isotherm, reaction kinetics

\section{INTRODUCTION}

In Egypt, industry represents a significant proportion of total wastewater discharges. The volume of water used by industry in Egypt in the year 2000 was estimated to be $6.1 \times 10^{9} \mathrm{~m}^{3}$, which is expected to be $8.6 \times 10^{9} \mathrm{~m}^{3} /$ year by the year 2025 [1]. Amongst the most highly polluting wastewater sources is the textile and dyeing industry which consumes large volumes of water primarily in the dyeing and finishing operations where dyes are extensively used [1]. The discharge of dye wastewater to receiving waters could potentially degrade water quality and impact on human health due to the toxic and carcinogenic effects of some dyes [2-4]. Methylene blue dye is a cationic dye discharged to the natural environment as a result of human activities. For instance, it is widely used in colouring paper, temporary hair colouring, dyeing cotton and wools, and coloring of paper stocks. The removal of such dye from any wastewater is of utmost importance due to the serious environmental damage that can occur as a result of contact with it. Even though Methylene blue is not considered to be a very toxic dye it can reveal very harmful effects on the living things, particularly in the case of people. After inhale symptoms such as difficulties in breathing, vomiting, diarrhea and nausea can occur in humans $[5,6]$.

As a result of the total ban on the importation of textile and leather products by the Government of Egypt, there has been increased activity in the local textile, finishing and dyeing industries to meet the demands for textile and coloured products. Large volumes of wastewater are therefore generated during the dyeing and finishing processes which are usually characterized by components high in both colour and organic content $[1,7]$. The majority of these dyes are synthetic in nature and are usually composed of aromatic rings in their structure, which makes them carcinogenic and mutagenic [8], inert and non-biodegradable when discharged into waste streams [9]. Therefore, the treatment of such wastewater containing soluble dyes requires virtually complete removal followed by safe disposal [10]. Sorption of coloured components from aqueous solutions has proven to be an excellent way to treat such effluents and is also a cost effective technique. Several studies have shown that numerous low-cost materials have been successfully applied in the removal of dyes from aqueous solution, some of which are peat for Basic Blue 69 and Acid Blue 25 
[9], giant duckweed for Methylene Blue [11], Neem leaf powder for Brilliant Green [12], rice husk for Malachite Green [13], sugar cane dust for basic dyes [14], tree fern for Basic Red 13[15], and Fuller's earth for Methylene Blue [16]. Mittal, Mittal, and Kurup ([17] applied the hen feather for Indigo Carmine removal. In addition, Bulut et al., [18] used bentonite for Congo Red removal. Mittal et al. [19] used activated charcoal for yellow ME 7 GL industrial dye effluent removal. Furthermore, carboxymethyl cellulose, polyvinyl alcohol and chemically treated rice husk biomass was used for the biosorption of Everdirect Orange-3GL and Direct Blue-67 dyes [20]. Additionally, Mittal et al. [21] applied hen feather as a cheap adsorbent material for wastewater effluent contaminated with Congo dye. However, it is noted from the literature there is a lack in the using of the bare palm branches as a cheap sorbent material.

The search for new, readily available and economical sorbents in developing countries, like Egypt, is ongoing to meet the purification needs for

\section{MATERIALS AND METHODS}

\subsection{Experimental Materials}

A simulated industrial textile wastewater was synthetically prepared using Methylene Blue Dyestuff $\left(\mathrm{C}_{16} \mathrm{H}_{18} \mathrm{~N}_{3} \mathrm{SCl} .3 \mathrm{H}_{2} \mathrm{O}\right.$; molecular weight: 373.9) supplied by Merck.

Bare palm branches were used as sorbent material to remove the dye. Received bare palm branches from El-Minia city, in the south of Egypt were first washed thoroughly with water to remove all foreign materials, dirt and fibers then cut it to small pieces of about 1 to $2 \mathrm{~mm}$ in size (16 to 8 BSS). The cleaned branches are dried at $383 \mathrm{~K}$ for 3 hours in a drying oven until it is completely dry. Chemically, the branches moisture content is $15.9 \%$, rich in organic matter $(92.99 \%)$. Ultimate analysis of branches which is carbon, nitrogen, sulphur, phosphorous and potassium was $53.94 \%, 0.78 \%$, $0.37 \%, 0.37 \%$ and $0.21 \%$, respectively.

The Brunauer-Emmett-Teller (BET) surface analysis which was carried using an automated adsorption apparatus (Micromeritics Pulse Chemisorbs 2705) shows $\left(9.13 \mathrm{~m}^{2} / \mathrm{g}\right.$ and $19.6 \mu \mathrm{m}$, values) for surface area and pore diameter, respectively.

\subsection{Experimental Methods}

\subsubsection{Isotherm experiment (Batch adsorption experiment)}

Equilibrium uptake of dye ions was investigated at $303 \mathrm{~K}$ with a sorbent mass of $1.0 \mathrm{~g}$ (16 BSS, particle size) of palm fibre in contact with $25 \mathrm{ml}$ of dye solutions which were prepared in distilled water at concentrations ranging from 100 to $400 \mathrm{mg} / \mathrm{L}$. The the large volume of textile industry effluents produced on a daily basis. One possible suitable sorbent for these wastes is the use of natural fibrous materials and research by Onwuka et al. [22] has shown that there is a considerable volume of household wastes and crop residues that might be suitable. According to their findings, over $66 \%$ of the palm kernel and its fibre are burnt, a little above 5\% is used as feed for animals and over $29 \%$ is left unused in the fields.

This study is aimed at investigating the possibility of using bare palm branches, a local readily available agricultural waste product in Egypt, for the removal of Methylene blue from aqueous solution. This class of dyes is the most problematic, because they tend to pass through conventional treatment systems unaffected. The system variables examined include: sorbent dose, initial concentration of the dye, and temperature. Isotherm studies for the batch experiments described below, and the development of an isotherm model, were undertaken. In addition, the kinetic order was investigated.

solution with the branches was mechanically shaken at $200 \mathrm{rpm}$ and $303 \mathrm{~K}$ for 5 hours. Thereafter, the samples were centrifuged at $400 \mathrm{rpm}$ for 15 minutes to separate the sorbent material. Subsequently, the equilibrium concentration of the dye remaining in solution was determined spectrophotometrically.

In this study, the adsorption data were analyzed using Langmuir and Freundlich adsorption isotherm models to describe the sorption equilibrium.

The Langmuir isotherm is based on the assumption that maximum adsorption corresponds to a saturated monolayer of solute molecules on the adsorbent surface. The linear form of the Langmuir isotherm is represented as follows:

$$
\frac{C_{e}}{q_{e}}=\frac{1}{K_{L} a_{L}}+\frac{1}{K_{L}} C_{e}
$$

where $\mathrm{C}_{\mathrm{e}}$ is the equilibrium dye concentration $\left(\mathrm{mg} \mathrm{L}^{-}\right.$ $\left.{ }^{1}\right), \mathrm{q}_{\mathrm{e}}$ is the mass of dye adsorbed per unit mass of adsorbent $\left(\mathrm{mg} \mathrm{g}^{-1}\right), \mathrm{K}_{\mathrm{L}}$ and $\mathrm{a}_{\mathrm{L}}$ are the Langmuir constants related to the adsorption capacity and rate of adsorption, respectively.

The Freundlich isotherm model is applicable to a highly heterogeneous surface:

$$
\ln \left(q_{e}\right)=\ln K_{F}+\frac{1}{n} \ln C_{e}
$$

where $K_{F}$ relate to the adsorption capacity of the adsorbent and $\mathrm{n}$ is a measure of the adsorption intensity. The magnitude of the coefficient, $1 / \mathrm{n}$, gives an indication of how favourable the adsorption is; values of $\mathrm{n}>1$ represent favorable adsorption conditions [9]. 


\subsubsection{Kinetic study}

The experimental set-up is principally consists of air compressor, flow meter and Perspex column (75 mm inside diameter and $600 \mathrm{~mm}$ height) and distributor $(5 \mathrm{~mm}$ thickness and $1.0 \mathrm{~mm}$ hole diameter). The column was filled with the dye solution before each run at concentrations ranging from 10 and $40 \mathrm{mg} / \mathrm{L}$ and the sorbent masses added were 1, 3, 4 and $5 \mathrm{~g}$ (16 BSS, particle size). A gas stirring technique was used to contact the sorbent and the dye solution. The fixed bed column was connected to an air supply system which enabled the air flow rate and temperature to be controlled. The kinetic studies describe the rate of adsorption and the time to reach equilibrium. Kinetic modelling is useful to optimize wastewater treatment design. Pseudo first order and second order kinetic models were examined for methylene blue adsorption by bare palm branches.

\subsection{Analytical Methods}

The residual dye concentrations of the samples were measured after the reaction time using a spectrophotometer (SHIMADZU-UV 1601, Model TCC-240A).

\section{RESULTS AND DISCUSSIONS \\ 3.1. Preliminary adsorption studies 3.1. 1. Effect of contact time}

The contact time studies were carried out to understand the trend of dye adsorption over a period of time at $40 \mathrm{mg} / \mathrm{L}$ dye concentration by taking fixed amount $(1.00 \mathrm{~g})$ and particle size $(16 \mathrm{BSS})$ of the bare palm branches. Figure 1 showed the amount of the dye adsorbed per unit mass of adsorbent $\left(\mathrm{q}_{\mathrm{t}}\right)$ increased with increasing time before reaching a plateau. The equilibrium is achieved after a contact time of approximately $4 \mathrm{~h}$. However, to allow some factor of safety at higher dye concentrations, all the experiments were carried out with $5 \mathrm{~h}$ of contact time. There was no noticeable improvement in dye removal when the contact time was prolonged. The initial high rate of dye uptake may be attributed to the existence of the bare surface; however, the number of available adsorption sites decreased as the concentration of dye adsorbed increased. This observation of 4 hours contact time was also reported by (Mittal, Jhare, and Mittal [21] for Eosin dye removal onto De-oiled waste Soya adsorbent.

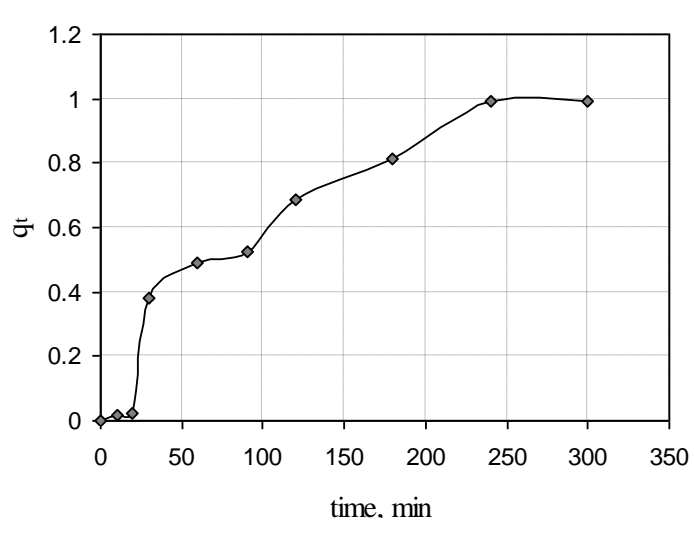

Fig. 1 Effect of contact time on the adsorption of dye by palm branches

\subsubsection{Effect of adsorbate concentration and temperature}

The adsorption behaviours of methylene blue dye on bare palm branches was examined in concentrations ranging from 100 to $400 \mathrm{mg} / \mathrm{L}$, at a fixed sorbent of $1.00 \mathrm{~g}$ of $16 \mathrm{BSS}$ particle size and $303 \mathrm{~K}$. The experimental results reveal that sorption was more favourable for the lower initial dye concentrations than the higher ones. This finding is due to the increase in availability of surface active sites resulting from the increased adsorbent/adsorbate ratio (Patil, Renukdas, and Patel 2011). This result in accordance with Gupta $t$ al., (2012b) for azo dye removal using $\mathrm{TiO}_{2}$, nevertheless, Mittal and Gupta (2010) recorded that the sorption of azo dye Eriochrome Black $\mathrm{T}$ onto bottom ash and de-oiled soya is increased with increasing the concentration uptake.

The adsorption was studied with initial dye concentration of $40 \mathrm{mg} / \mathrm{L}$, temperatures 303, 343, 353 and $363 \mathrm{~K}$, using adsorbent mass of one $\mathrm{g}$ (16BSS, particle size) with constant shaking (200 rpm, $5 \mathrm{hr}$ ) to illustrate the effect of temperature on the sorption isotherm. Fig. 2 represented that sorption capacity decreased with an increase in temperature. This decrease in sorption capacity with temperature is due to the enhancement of the desorption step in the sorption mechanism indicating that the process is exothermic (Demirbas et al., 2007). It is known that decreasing sorption capacity with increasing temperature is mainly due to the weakening of sorptive forces between the active sites on the palm kernel fibre and anionic dye species, and also between adjacent dye molecules on the sorbed phase. The conventional mechanism of a physisorption system is that an increase in temperature usually increases the rate of approach to equilibrium, but decreases the equilibrium capacity [14]. However, this finding is not in agreement with Mittal et al. [21] who found the reaction is endothermic in the treatment of dyes using de-oiled soya and hen feather, respectively. 


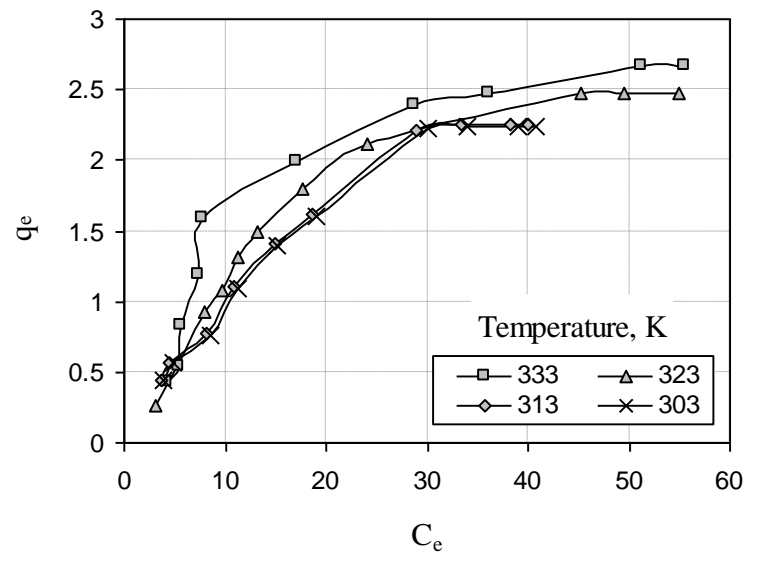

Fig. 2 Effect of temperature variation on the dye adsorption

\subsubsection{Effect of mass and particle size of sorbent}

The effect of the sorption capacity on the removal of methylene bue dye was examined by varying the sorbent masses of 1.0, 2.0, 3.0 and $5.0 \mathrm{~g}$ by fixing other conditions. It is apparent from (Fig. 3a) that by increasing the dose of the bare palm branches, the number of sorption sites available for sorbent interaction is increased, thereby resulting in the increased percentage dye removal from the solution. The decrease in sorbent capacity may be attributed to: (a) the increase in sorbent dose at constant dye concentration and volume leads to unsaturation of sorption sites [22]; (b) particulate interaction such as aggregation resulting from high sorbent dose [23]. Such aggregation would result in a decrease in total surface area of the sorbent and an increase in diffusional path length [24]. Those results of increasing the sorption capacity with increasing the sorbent amount in agreement with the previous findings of Mittal et al. [21].

Three different particle sizes, 16, 14 and 8 BSS, of bare palm branches (1.00 $\mathrm{g}$ of adsorbent, $40 \mathrm{mg} / \mathrm{L}$ dye solution concentration) were examined to investigate the effect of particle size on the sorption process (Fig. 3b).

The maximum sorption capacity was achieved at 16 BSS particle size. The increase in the particle size may lead to unsaturation of sorption sites and particulate interaction such as aggregation resulting from high sorbent dose [ 22, 24]. Thus, total surface area of the sorbent is decreased and an increase in the diffusional path length due to the decrease in available surface area [24].

For larger particles, the diffusion resistance to mass transfer is high and most of the internal surface of the particle may not be utilized for adsorption and so the amount of dye adsorbed is relatively small.

This phenomenon of increasing the sorption capacity with decreasing the adsorbent size was previously mentioned by Mittal, Jhare, and Mittal [25] for dye sorption with de-oiled waste soya.

\subsection{Adsorption isotherms}

The adsorption isotherm is the relationship between the amount of a substance adsorbed and its concentration in the equilibrium solution at a constant temperature.

The applicability of the isotherm models, namely Langmuir and Freundlich, to the adsorption study was assessed by comparing the correlation coefficients, $\mathrm{R}^{2}$ values.

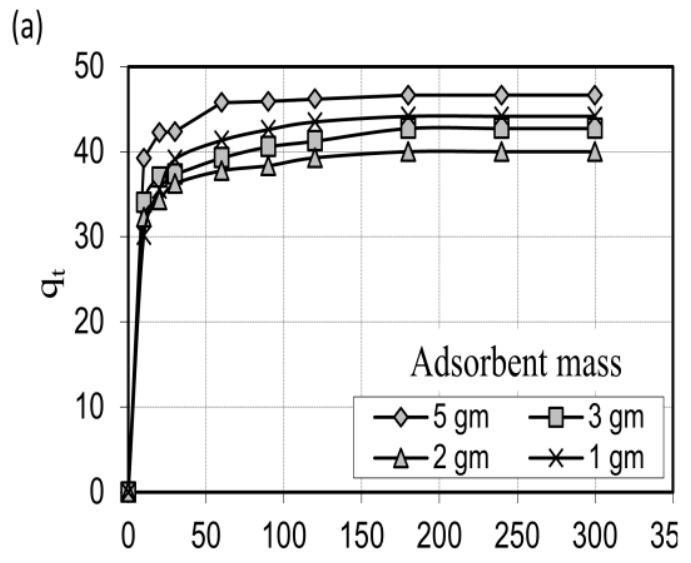

Time, $\min$

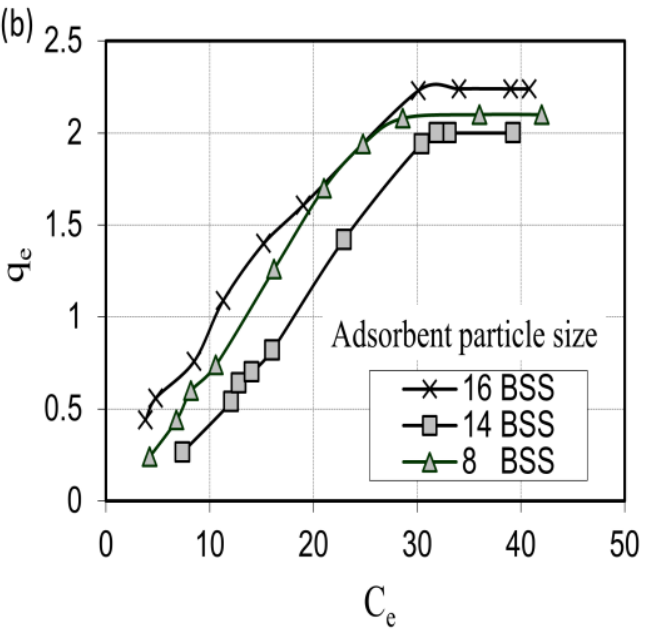

Fig. 3 Effect of sorbent material on sorption process: (a) effect of sorbent mass; (b) effect of sorbent particle size 
As shown in Fig. 4 Langmuir isotherm was chosen to show the maximum adsorption capacity. The values of maximum adsorption capacity can be obtained from the slope of the plot of $\mathrm{C}_{\mathrm{e}} / \mathrm{q}_{\mathrm{e}}$ versus $\mathrm{C}_{\mathrm{e}}$.

The correlation coefficient of the Langmuir isotherm, $\mathrm{R}^{2}$ is 0.94 . The essential characteristics of the Langmuir isotherm can be expressed in terms of a dimensionless constant as shown in Table 1 for different conditions.

In addition, Freundlich isotherm is applied by plotting of $\ln \mathrm{q}_{\mathrm{e}}$ versus $\ln \mathrm{C}_{\mathrm{e}}$ in Fig. 4 shows a straight line with a correlation coefficient of 0.98 . The constants $K_{F}$ and $1 / n$ were determined from the plot and are presented in Table 1.

Table1 Comparison of Langmuir and Freundlich constants for the dye adsorption on bare palm branches

\begin{tabular}{|c|c|c|c|c|c|c|c|}
\hline \multirow[t]{2}{*}{ Adsorption condition } & \multicolumn{4}{|c|}{ Langmuir } & \multicolumn{3}{|c|}{ Freundlich } \\
\hline & $\begin{array}{c}\mathrm{K}_{\mathrm{L}}, \\
\left(\mathrm{dm}^{3} / \mathrm{g}\right)\end{array}$ & $\begin{array}{c}\mathrm{a}_{\mathrm{L}}, \\
\left(\mathrm{dm}^{3} / \mathrm{mg}\right)\end{array}$ & $\begin{array}{c}\mathrm{q}_{\max }, \\
(\mathrm{mg} / \mathrm{g})\end{array}$ & $\mathrm{R}^{2}$ & $\begin{array}{c}\mathrm{K}_{\mathrm{F}}, \\
\left(\mathrm{dm}^{3} / \mathrm{g}\right)\end{array}$ & $\mathrm{n}$ & $\mathrm{R}^{2}$ \\
\hline$\left(2.0 \mathrm{~mm}\right.$ particle size, $\left.30{ }^{\circ} \mathrm{C}\right)$ & 0.041 & 0.0097 & 4.17 & 0.49 & 0.023 & 0.79 & 0.97 \\
\hline$\left(1.2 \mathrm{~mm}\right.$ particle size, $\left.30{ }^{\circ} \mathrm{C}\right)$ & 0.735 & 0.0051 & 14.30 & 0.13 & 0.069 & 1.11 & 0.95 \\
\hline$\left(1.0 \mathrm{~mm}\right.$ particle size, $\left.30{ }^{\circ} \mathrm{C}\right)$ & 0.129 & 0.0303 & 4.277 & 0.94 & 0.182 & 1.41 & 0.98 \\
\hline$\left(1.0 \mathrm{~mm}\right.$ particle size, $\left.40{ }^{\circ} \mathrm{C}\right)$ & 0.137 & 0.3282 & 4.185 & 0.95 & 0.193 & 1.43 & 0.98 \\
\hline$\left(1.0 \mathrm{~mm}\right.$ particle size, $\left.50{ }^{\circ} \mathrm{C}\right)$ & 0.146 & 0.0372 & 3.918 & 0.86 & 0.192 & 1.42 & 0.86 \\
\hline$\left(1.0 \mathrm{~mm}\right.$ particle size, $\left.60{ }^{\circ} \mathrm{C}\right)$ & 0.167 & 0.0433 & 3.849 & 0.89 & 0.273 & 1.65 & 0.82 \\
\hline
\end{tabular}

$\mathrm{R}^{2}$ : Correlation factor

As seen from Table 1, a high regression correlation coefficient was shown by the Freundlich model, and indicates that the Freundlich model was suitable for describing the sorption equilibrium of dye by bare palm. Similar results were reported for dye adsorption on powder and flakes chitosan [26].

\subsection{Adsorption kinetics}

The study of the adsorption kinetics describes the resistance to solute transfer from the solution to the boundary layer at the solid-liquid interface to the pore water and then to the solid.

It is well known that adsorption kinetics is mainly controlled by the following steps:

1. Solute molecules transfer from the solution to the boundary film;

2. Solute molecules transfer from the film to the surface of the sorbent (external diffusion);
3. Diffusion from the surface to intra-particle sites and

4. Interaction of solute molecules with the available sites on the internal surface [27].

The evolution of the adsorption process can be followed by measuring the number of particles adsorbed per unit time. Many kinetic models have been proposed for the adsorption of solutes on solids. They include, amongst others, the pseudofirst order kinetic model and the pseudo-second order model. Examination of the results presented in Table 2 shows that the adsorption data fitted best to the pseudo-second order rate equation since the correlation coefficient is close to one and higher than that for the first order. 
(a)

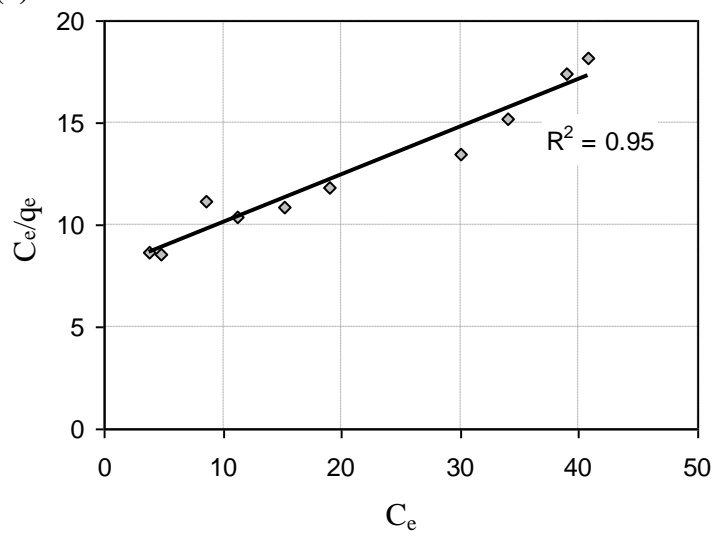

(b)

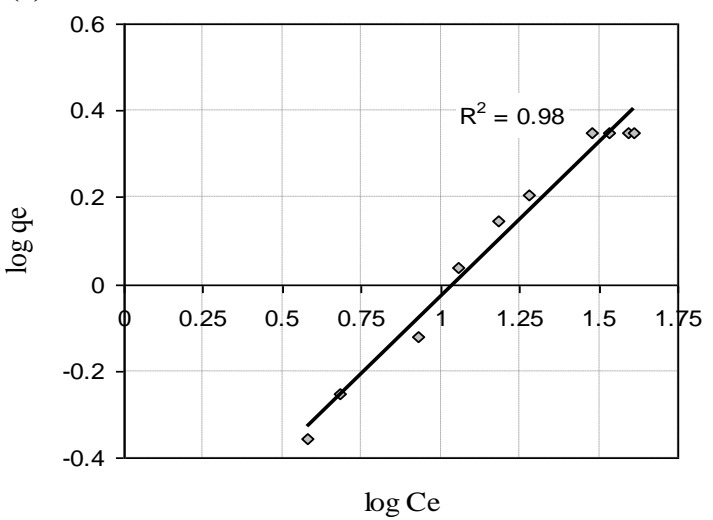

Fig. 4 Isothermal curves of bare palm adsorption $\left(1.0 \mathrm{~mm}\right.$ particle size, $\left.30{ }^{\circ} \mathrm{C}\right)$

(a) Langmuir (b) Freundlich

Table 2Comparison of first and second order reaction kinetic constants for the dye adsorption on the bare palm branches

\begin{tabular}{|c|c|c|c|c|c|c|}
\hline \multicolumn{3}{|c|}{ Adsorption condition } & \multicolumn{2}{|c|}{$\begin{array}{l}\text { Pseudo-first order kinetic } \\
\text { model }\end{array}$} & \multicolumn{2}{|c|}{ Pseudo-second order kinetic model } \\
\hline $\begin{array}{l}\text { Air flow rate } \\
\left(\mathrm{cm}^{3} / \mathrm{min}\right)\end{array}$ & $\begin{array}{l}\text { Initial } \\
\text { concentration } \\
\text { Of the dye } \\
\left(\mathrm{mg} / \mathrm{dm}^{3}\right)\end{array}$ & $\begin{array}{l}\text { Mass } \\
\text { adsorbent } \\
(\mathrm{g})\end{array}$ & $\begin{array}{c}\mathrm{K}_{1}\left(* 10^{2}\right), \\
\left(\min ^{-1}\right)\end{array}$ & $\mathrm{R}^{2}$ & $\begin{array}{l}\mathrm{K}_{2}\left(* 10^{3}\right), \\
\left(\mathrm{g} \cdot \mathrm{mg}^{-1} \mathrm{~min}^{-1}\right)\end{array}$ & $\mathrm{R}^{2}$ \\
\hline 20 & 376.8 & 5.0 & -0.008 & 0.3 & 0.0066 & 0.001 \\
\hline 40 & 376.8 & 5.0 & -0.009 & 00.6 & 0.0076 & 0.99 \\
\hline 60 & 376.8 & 5.0 & -0.008 & 0.6 & 0.0076 & 0.99 \\
\hline 80 & 376.8 & 5.0 & -0.005 & 0.3 & 0.0012 & 0.99 \\
\hline 80 & 97.8 & 5.0 & -0.008 & 0.2 & 0.0200 & 0.99 \\
\hline 80 & 198.7 & 5.0 & -0.020 & 0.8 & 0.0039 & 0.99 \\
\hline 80 & 296.5 & 5.0 & -0.008 & 0.5 & 0.0025 & 0.99 \\
\hline 80 & 376.8 & 5.0 & -0.01 & 0.3 & 0.0120 & 0.99 \\
\hline 80 & 376.8 & 1.0 & -0.008 & 0.6 & 0.0050 & 0.99 \\
\hline 80 & 376.8 & 2.0 & -0.009 & 0.9 & 0.0080 & 0.99 \\
\hline 80 & 376.8 & 3.0 & -0.009 & 0.6 & 0.0060 & 0.99 \\
\hline 80 & 376.8 & 5.0 & -0.008 & 0.3 & 0.0012 & 0.99 \\
\hline
\end{tabular}

$\mathrm{R}^{2}$ : Correlation factor; $\mathrm{K}_{1}$ and $\mathrm{K}_{2}$ are first and second reaction kinetics, respectively

\section{Conclusions}

The present study demonstrated that bare palm branches, which are abundantly available in Egypt, is an efficient sorbent for the removal of dye in water and it may be an alternative to more costly adsorbents such as activated carbon. The batch studies clearly suggest that bare palm sorbent exhibits almost $100 \%$ adsorption at lower concentrations of the dye. Equilibrium data fitted well with the Freundlich model, which suggests a heterogeneous coverage of dye molecules on the surface of the bare palm branches. Moreover, the kinetic data were best fitted to pseudo-second order kinetic model.

\section{References}

[1] Abdel-Shafy, H., and R. Aly. 2002. Water Issue in Egypt: Resources, Pollution and Protection Endeavors, CEJOEM 8: 1, 3-21.

[2] Georgiou, D., P. Melidis, and A. Aivasidis. 2002. Gimouhopoulos, K. Degradation of azo-reactive dyes by ultraviolet radiation in the presence of hydrogen peroxide. Dyes Pigments 52, 69-78.

[3] Daneshvar, N., and A. Khataee. 2006. Removal of Azo Dye C.I. Acid Red 14 from Contaminated Water using Fenton, UV/ $\mathrm{H}_{2} \mathrm{O}_{2}, \mathrm{UV} / \mathrm{H}_{2} \mathrm{O}_{2} / \mathrm{Fe}(\mathrm{II})$, $\mathrm{UV} / \mathrm{H}_{2} \mathrm{O}_{2} / \mathrm{Fe}(\mathrm{III})$ and $\mathrm{UV} / \mathrm{H}_{2} \mathrm{O}_{2} / \mathrm{Fe}(\mathrm{III}) / O x a l a t e$ 
Processes: A Comparative Study. Journal of Environmental Science and Health 41, 315-328.

[4] Muthuraman, G. and K. Palanivelu. 2006. Transport of textile dye in vegetable oils based supported liquid membrane. Dyes Pigments 70, 99104.

[5] Pirkannicmi K. and M. Sillanpaa. 2002. Heterogeneous water phase catalysis as an environmental application: a review. Chemosphere 48: 1047.

[6] Altaher, H., and E. ElQada. 2011. Investigation of the treatment of colored water using efficient locally available adsorbent. Intational Journal Energy Environment 2(6): 1113-24.

[7] Papic, S., N. Koprivanac, A. Bozic, and A. Metes, 2004. Removal of some reactive dyes from synthetic wastewater by combined $\mathrm{Al}$ (III) coagulation/carbon adsorption process. Dyes Pigments 62:3, 291-298.

[8] Mittal, A., and S. Gupta. 1996. Biosorption of cationic dyes by dead macro fungus Fomitopsis carnes: batch studies. Water Science and Technology 34: 10, 81-87.

[9] Ho Y. and G. McKay. 1998. Sorption of dye from aqueous solution by peat. Chemical Engineering Journal 70, 115-124.

[10] Weber, W., and J. Morris. 1964. Advances in water pollution research. New York: Pergamon Press.

[11] Waranusantigul, P., P. Pokethitiyook, M. Kruatrachue, and E. Upatham. 2003. Kinetics of basic dye (Methylene blue) biosorption by giant duckweed (Spirodela polyrrhiza). Environmental Pollution, 125 (3): 385-92.

[12] Bhattacharyya, K. and A. Sarma. 2003. Adsorption characteristics of the dye, Brilliant Green, on neem leaf powder. Dyes Pigments 5: 3, 211-222.

[13] Guo, Y., H. Zhang, N. Tao, Y. Liu, J. Qi, and Z. Wang. 2003. Adsorption of malachite green and iodine on rice husk-based porous carbon. Material Chemistry and Physics 82: 1, 107-115.

[14] Ho, Y., W. Chiu, and C.Wang. 2005a. Regression analysis for the sorption isotherms of basic dyes on sugarcane dust. Bioresource Technology 96: 11, 1285-1291.

[15] Ho, Y., T. Chiang, and Y. Hsueh. 2005b. Removal of basic dye from aqueous solution using tree fern as a biosorbent. Process Biochemistry 40: 1, 119-124.
[16] Atun, G., G. Hisarli, W. Sheldrick, and M. Muhler. 2003. Adsorptive removal of Methylene blue from colored effluents on fuller's earth. Journal of Colloid Interface Science 261: 1, 32-39.

[17] Mittal, A., J. Mittal and L. Kurup. 2007. Utilization of Hen Feathers for the Adsorption of Indigo Carmine from Simulated Effluents. Journal of Environmental Protection Science 1: 92-100.

[18] Bulut, E., M. Ozacar, I. Ayhan, and A. Sengil. 2008. Equilibrium and kinetic data and process design for adsorption of Congo Red onto bentonite, Journal of Hazardous Material 154, 613-622.

[19] Mittal, A. and V. Gupta. 2010. Adsorptive removal and recovery of the azo dye Eriochrome Black T, Toxicological and Environmental Chemistry 92 (10): 1813-1823.

[20] Safa, Y., and H. Bhatti. 2011. Adsorptive removal of direct dyes by low cost rice husk: Effect of treatments and modifications, African Journal of Biotechnology 10: 16, 3128-3142.

[21] Mittal, A., D., Jhare, and J. Mittal. 2013. Adsorption of hazardous dye Eosin Yellow from aqueous solution onto waste material De-oiled Soya: Isotherm, kinetics and bulk removal. Journal of Molecular Liquids 179: 133-140

[22] Onwuka, C., P. Adetiloye, and C. Afolami. 1997, Use of household wastes and crop residues in small ruminant feeding in Nigeria. Small Ruminant Research 24: 3, 233-237.

[23] Ozacar M., and I. Sxengil. 2005. Adsorption of metal complex dyes from aqueous solutions by pine sawdust. Bioresource Technology 96: 7, 791795.

[24] Shukla A., Y. Zhang, P. Dubey, J. Margrave, and S. Shukla. 2002. The role of sawdust in the removal of unwanted materials from water. Journal of Hazardous Materials 95: 1-2, 137-52.

[25] Mittal, A., R. Jain, J. Mittal, S. Varshney, and S. Sikarwar. 2010. Removal of Yellow ME 7 GL from industrial effluent using electrochemical and adsorption techniques. Int. J. of Environment and Pollution 43 (4):.308-323.

[26] Ahmad, A., S. Bhatia, N. Ibrahim, and S. Sumathi. 2005. Adsorption of residual oil from palm oil mill effluent using rubber powder. Brazilian Journal of Chemical Engineering 22: 3, 371-379.

[27] Demirbas, E., M. Kobya, E. Senturk, and T. Ozkan. 2007. Adsorption Kinetics for the Removal of Chromium(VI) from Aqueous Solutions on the Activated Carbons prepared from Agricultural Wastes. Water SA 30 (4), 533-539. 